\title{
Effect of sieving and sample storage on soil respiration and its temperature sensitivity (Q10) in mineral soils from Germany
}

\author{
N. Meyer ${ }^{1,2}$ (I) G. Welp ${ }^{1} \cdot$ W. Amelung ${ }^{1}$
}

Received: 20 September 2018 / Revised: 5 June 2019 / Accepted: 17 June 2019/Published online: 26 June 2019

(C) The Author(s) 2019, corrected publication 2019

\begin{abstract}
Knowledge about spatial patterns of soil respiration (SR) and its temperature sensitivity (Q10) is of emerging relevance for assessing carbon fluxes across the landscape. Related experiments are often conducted under controlled laboratory conditions and usually rely on soil samples, which are sieved and stored. Here, we investigated the effect of sieving and storage on SR and Q10. We took 14 samples from different land use types and soil textures. Samples were sieved to $2 \mathrm{~mm}$ at field-moist conditions and split into four treatments: sieved/no-storage, sieved/freeze-storage $\left(-18{ }^{\circ} \mathrm{C}\right)$, sieved/cold-storage $\left(+4{ }^{\circ} \mathrm{C}\right)$, and sieved/drystorage $\left(+40^{\circ} \mathrm{C}\right)$. The storage time was 7 weeks. Intact soil cores were used as a control. The SR was not significantly affected by sieving/no-storage, sieving/freeze-storage, and sieving/cold-storage compared with the control. Yet, sieving/dry-storage significantly increased SR but all samples were similarly affected $(r=0.81$ for the correlation between SR after sieving/dry-storage and $\mathrm{SR}$ in the control). The Q10 of sieving/no-storage (1.94 \pm 0.28$)$, sieving/freeze-storage (1.94 \pm 0.23$)$, sieving/cold-storage ( 2.37 $\pm 0.29)$, and sieving/dry-storage (2.29 \pm 1.35$)$ did not differ significantly from the control $(2.12 \pm 0.23)$. All samples responded similar to sieving and storage $(r=0.68-0.73$ for the correlation between Q10 in each respective treatment and Q10 in the control), with the exception of sieved/dry-storage $(r=0.09)$. We conclude that sieving at field-moist conditions and subsequent freeze- or cold-storage is acceptable to derive SR and Q10 for the here reported storage time. Although dry-storage may be acceptable for the comparison of SR between samples, it should be avoided for realistic estimates of SR and for the determination of Q10.
\end{abstract}

Keywords Heterotrophic soil respiration $\cdot$ Carbon mineralization $\cdot$ Soil pretreatment $\cdot$ Drying and rewetting

\section{Introduction}

Heterotrophic soil respiration (SR) is a major component of the global carbon (C) cycle and an accurate assessment of its spatiotemporal patterns is of immense importance for predicting $\mathrm{C}$ fluxes. One of the major regulating factors of $\mathrm{SR}$ is temperature. The relation between SR and temperature

Electronic supplementary material The online version of this article (https://doi.org/10.1007/s00374-019-01374-7) contains supplementary material, which is available to authorized users.

N. Meyer

nele.meyer@helsinki.fi

1 Institute of Crop Science and Resource Conservation, Soil Science and Soil Ecology, University of Bonn, Nussallee 13,

53115 Bonn, Germany

2 Department of Forest Sciences, University of Helsinki, Latokartanonkaari 7, 00790 Helsinki, Finland is commonly expressed as Q10 value, which is the increase of SR by a $10{ }^{\circ} \mathrm{C}$ rise in temperature (Kirschbaum 1995; Van 't Hoff 1898). While the Q10 value is commonly implemented as a fixed value of 1.5 or 2 in modeling approaches (Foereid et al. 2014; Potter et al. 1993; Raich et al. 1991), there is consensus that Q10 can be highly variable and might range from 1 to higher than 12 (Hamdi et al. 2013). Many studies have been conducted to explore spatiotemporal patterns of SR and Q10 values across the landscape (e.g., Fierer et al. 2006; Wang et al. 2016). Many of these studies were conducted under controlled laboratory conditions in order to vary the factor of interest (e.g., temperature) while keeping interfering factors constant (e.g., Fierer et al. 2006; Lefèvre et al. 2014; Wang et al. 2016). In this regard, Kirschbaum (2006) considered that "laboratory incubations would provide the best and least biased, basis for estimating the temperature dependence of organic matter decomposition." Other researchers, however, questioned the transferability of controlled laboratory experiments to real-world conditions (Černohlávková et al. 2009; Herbst et al. 2016; Lamparter et al. 2009; Lomander 
et al. 1998). The authors criticized that sample preprocessing like sieving and storage might alter microbial biomass, microbial activity, microbial community composition, and the availability of substrate. However, storage is mostly inevitable for practical reasons (e.g., Gritsch et al. 2015; Lefèvre et al. 2014; Meyer et al. 2017) and sieving (mostly to $<2 \mathrm{~mm}$ ) is a common practice to remove roots, plant residues, and rock fragments and to ensure homogenization of the soil (e.g., Conant et al. 2008; Fierer et al. 2006; Wang et al. 2016). Only few studies on Q10 were conducted using undisturbed and/or fresh samples (e.g., Miller and Geisseler 2018; Reichstein et al. 2005)

An alteration of SR and Q10 by sieving and storage might be straightforward if all soils were similarly affected. In this case, a correction factor could be applied to derive the realworld values. However, Hassink (1992) reported that sieving has larger effects in loamy than in sandy soils and Lee et al. (2007) reported that soils with high organic carbon (SOC) contents are more susceptible to storage than soils with low SOC contents. Hence, sieving and storage might not only induce an offset in SR and Q10 estimates but might also lead to false conclusions about relations and comparisons among samples and, hence, to false conclusions about spatial patterns. Several studies have been conducted to investigate the effect of sieving (e.g., Datta et al. 2014; Hassink 1992; Juarez et al. 2013; Thomson et al. 2010) or storage (Černohlávková et al. 2009; Stenberg et al. 1998; Zelles et al. 1991) on SR. One major drawback of previous studies is that SR, which was measured after various preprocessing treatments, has often not been compared with an undisturbed and non-stored control, which might represent the "real-world" conditions (e.g., Černohlávková et al. 2009; Datta et al. 2014; Stenberg et al. 1998; Zelles et al. 1991). Further, the effect of sieving and storage on the temperature sensitivity of SR (Q10) has, to our knowledge, not been investigated yet.

The aim of this study was to investigate the effect of sieving and storage on SR and Q10. We hypothesized that (1) sieving and storage have a significant effect on SR and Q10 and that (2) soils that vary in texture and SOC contents respond with different extent to sieving and storage, which complicates comparisons between samples and interpretations of spatial patterns. To investigate these hypotheses, we took 14 soil samples including different land use types and textures in North Rhine-Westphalia, Germany. Samples were sieved at field-moist conditions and split into four treatments: no storage, freeze-storage, cold-storage, and dry-storage. Samples were stored for 7 weeks. Intact soil cores, which were neither sieved nor stored, were used as a control.

\section{Material and methods}

We sampled 14 sites in North Rhine-Westphalia (Germany), including 5 cropland sites, 4 grassland sites, and 5 forest sites, showing a broad range of soil textures and SOC contents (7$96 \%$ sand, $1-33 \%$ clay, $1.1-4.8 \%$ SOC, for details see Table S1). At each site, 20 soil cylinders of $100 \mathrm{~cm}^{3}$ were taken from the A horizon (1-5 cm depth). Five soil cylinders remained intact, which were put into polyethylene incubation vessels immediately after sampling ("control" = not sieved, not stored). Soil contained within the remaining soil cylinders was combined to a composite sample and subsequently sieved to $<2 \mathrm{~mm}$ at field-moist conditions (within $24 \mathrm{~h}$ after sampling). Parts of each composite sample were homogenized using a kitchen hand mixer. Subsequently, $80 \mathrm{~g}$ of moist soil was filled into incubation vessels (sieved/non-stored, Table 1), three replications each, and slightly recompressed (following Breulmann et al. 2014). Mixing was conducted because in many studies it represents a common practice to homogenize the soil (Meyer et al. 2017; Smith 2005). The incubation vessels containing soil of the control and of the sieved/non-stored treatment were subsequently pre-incubated at field-moist conditions for 6 days at $4{ }^{\circ} \mathrm{C}$. Thereafter, they were placed into a Respicond system for respiration measurements (see below).

The remaining soil of each sieved composite sample was split into three parts and stored for 7 weeks (a) at $4{ }^{\circ} \mathrm{C}$ in a cold room (sieved/cold-storage, Table 1), (b) at $-18{ }^{\circ} \mathrm{C}$ in a freezer (sieved, freeze-storage), or (c) were dried at $40{ }^{\circ} \mathrm{C}$ and then stored for 7 weeks at room temperature (sieved/dry-storage). After 7 weeks, the samples of the stored treatments were thawed at $4{ }^{\circ} \mathrm{C}$ (sieved/freeze-storage treatment) or rewetted to the original soil moisture level of the intact control (sieved/dry-storage treatment). Samples were homogenized with a kitchen hand mixer. Subsequently, $80 \mathrm{~g}$ moist soil was filled into incubation vessels, three analytical replications each, and slightly recompressed. Like the non-stored treatments, they were preincubated at $4{ }^{\circ} \mathrm{C}$ for 6 days and subsequently placed into the Respicond system for respiration measurements (see below).

Soil respiration measurements were conducted using an automated respirometer that allows incubating 95 samples in parallel (Respicond VIII, Nordgren Innovations AB, Sweden). The system provides a continuous measurement of $\mathrm{CO}_{2}$ evolution by trapping $\mathrm{CO}_{2}$ in potassium hydroxide (KOH) (Nordgren 1988). The decrease in electrical conductivity in $\mathrm{KOH}$ solution caused by $\mathrm{CO}_{2}$ entrapment was automatically measured every hour by platinum electrodes. The changes in conductivity were automatically transformed to $\mathrm{CO}_{2}$ evolution rates, based on Eq. 1 where $A$ is a conductivity constant that depends on the molarity of the $\mathrm{KOH}$ solution, $C_{t 0}$ is the conductance of the fresh $\mathrm{KOH}$ measured at the beginning of the incubation time, and $C_{t 1}$ is the conductance at time $t$. We are aware that autotrophic bacteria can take up parts of the produced $\mathrm{CO}_{2}$, which may lead to underestimations of soil respiration and, as temperature dependent process, may induce a bias in Q10 estimates. Yet, as measured $\mathrm{CO}_{2}$ production is considerably larger than rates of $\mathrm{CO}_{2}$ 
Table 1 Details of the treatments and mean values and standard deviation of soil respiration rates at $25^{\circ} \mathrm{C}\left(\mathrm{SR}_{25}\right)$ and Q10 values. In each column, values with different letters are significantly different $(\mathrm{p}<0.05)$

\begin{tabular}{|c|c|c|c|c|c|c|c|}
\hline Treatment & Sieving & Storage time & $\begin{array}{l}\text { Storage } \\
\text { temperature }\end{array}$ & $\begin{array}{l}\text { Independent } \\
\text { samples }\end{array}$ & $\begin{array}{l}\text { Replicates per } \\
\text { sample }\end{array}$ & $\begin{array}{l}\mathrm{SR}_{25} \\
\left(\mu \mathrm{g} \mathrm{CO}_{2} \mathrm{~h}^{-1} \mathrm{~g}^{-1} \text { soil }\right)\end{array}$ & Q10 value \\
\hline Control & No & No & - & 14 & 5 & $3.04 \pm 1.64^{\mathrm{a}}$ & $2.20 \pm 0.23^{\mathrm{ab}}$ \\
\hline Sieved/non-stored & Yes & No & - & 14 & 3 & $3.38 \pm 1.62^{\mathrm{a}}$ & $1.94 \pm 0.28^{\mathrm{b}}$ \\
\hline Sieved/freeze-storage & Yes & 7 weeks & $-18^{\circ} \mathrm{C}$ & 14 & 3 & $3.57 \pm 1.71^{\mathrm{a}}$ & $1.94 \pm 0.23^{\mathrm{b}}$ \\
\hline Sieved/cold-storage & Yes & 7 weeks & $4^{\circ} \mathrm{C}$ & 14 & 3 & $2.57 \pm 1.15^{\mathrm{a}}$ & $2.37 \pm 0.29^{\mathrm{a}}$ \\
\hline Sieved/dry-storage & Yes & 7 weeks & $40{ }^{\circ} \mathrm{C}$ & 14 & 3 & $6.46 \pm 3.07^{\mathrm{b}}$ & $1.94 \pm 0.40^{\mathrm{b}}$ \\
\hline
\end{tabular}

fixation reported by Xiao et al. (2018), we assume this process to have a negligible influence on the outcome.

$\mathrm{CO}_{2}=A \times \frac{C_{t 0}-C_{t 1}}{C_{t 0}}$

After pre-incubation at $4{ }^{\circ} \mathrm{C}$ for 6 days, soil samples were sequentially set to $5{ }^{\circ} \mathrm{C}, 10{ }^{\circ} \mathrm{C}, 15^{\circ} \mathrm{C}, 20^{\circ} \mathrm{C}$, and $25^{\circ} \mathrm{C}$ by controlling the temperature of the water bath of the Respicond system. Samples were kept at each temperature for $24 \mathrm{~h}$ (see also Gritsch et al. 2015). The first $12 \mathrm{~h}$ after each temperature rise were treated as equilibration time. This was necessary because soil microorganisms may need a couple of hours to adapt to the new temperature level. The subsequent $12 \mathrm{~h}$ were used for the calculation of soil respiration. After completion of each temperature level, vessels were left open for about $30 \mathrm{~min}$ to equilibrate with ambient $\mathrm{O}_{2}$ concentrations. The $\mathrm{KOH}$ solution was replaced subsequently. The short-term incubation approach was chosen to minimize effects of changing $\mathrm{C}$ pool sizes during the incubation. Longer incubation times can underestimate Q10 because SOC decreases with increasing incubation time (Hamdi et al. 2013; Kirschbaum 2006).

Soil respiration was expressed as the average hourly $\mathrm{CO}_{2}$ release per gram of dry fine soil $(<2 \mathrm{~mm})$. The exact amount of dry fine soil in each incubation vessel may vary as a result of variable soil moisture and particles $>2 \mathrm{~mm}$. Hence, the soil contained within each incubation vessel was dried and, in case of the control, sieved to $<2 \mathrm{~mm}$ after completion of the incubation.

An exponential equation was used to calculate the relationship between temperature and soil respiration, which was fitted over the total temperature range of $5-25{ }^{\circ} \mathrm{C}$ according to Eq. 2 where $\mathrm{SR}_{T}$ is soil respiration at a given temperature, $a$ and $b$ are fitted parameters, and $T$ is temperature.

$\mathrm{SR}_{T}=a \times \exp ^{b \times T}$

The Q10 value was then calculated by inserting parameter $b$ into Eq. 3.

$Q 10=\exp ^{10 \times b}$

The mean value of the 3-5 analytical replicates per sampling site and treatment was used for statistical tests. One sample was excluded from statistical tests because it showed an irregular response to temperature in the sieved/dry-storage treatment. We used one-way ANOVA with sampling site as a block factor to investigate whether Q10 or SR was significantly different across treatments. In case of significant effects $(p<0.05)$, Tukeys HSD post hoc test was applied to investigate the significances between different treatments. Statistics and figures were performed with $\mathrm{R}$ (version 3.2.3, R Core Team 2013).

In each treatment, soil was incubated at the original soil moisture level of each respective control sample (Table S1). Hence, soil moisture varied across samples but not across treatments. As the goal of this study was to explore the effect of sieving and storage in comparison with undisturbed soil under non-manipulated conditions, we have to accept this natural variation in water content. Almost all of the samples were within the range of 30-52\% of water holding capacity (WHC, see Table S1) and hence, in a range in which neither water deficiency nor oxygen deficiency severely limits SR (Meyer et al. 2018). Thus, we expect no major effect of variable soil moisture contents on soil respiration. Only three samples do not fulfill this criterion (21-28\% of WHC). But as excluding these samples does not affect the results, we are confident that the here considered variations in water content have no major effect on the response of SR to sieving and storage.

\section{Results and discussion}

\section{Effect of sieving and storage on soil respiration at $25{ }^{\circ} \mathrm{C}$}

Sieving the soil at field-moist conditions did not significantly alter soil respiration at $25{ }^{\circ} \mathrm{C}\left(\mathrm{SR}_{25}\right)$ relative to the control (Table 1, Fig. 1a, $p=0.99$ ). This finding is in agreement with results from Černohlávková et al. (2009) and Thomson et al. (2010), who also reported that sieving at field-moist conditions did not significantly affect SR. Other studies, in contrast, suggested that sieving may result in a temporary increase of SR as aggregates are disrupted, which releases previously stabilized SOC (Hassink 1992). However, Hassink (1992) assumed that the degree of disruption is larger in dried samples 

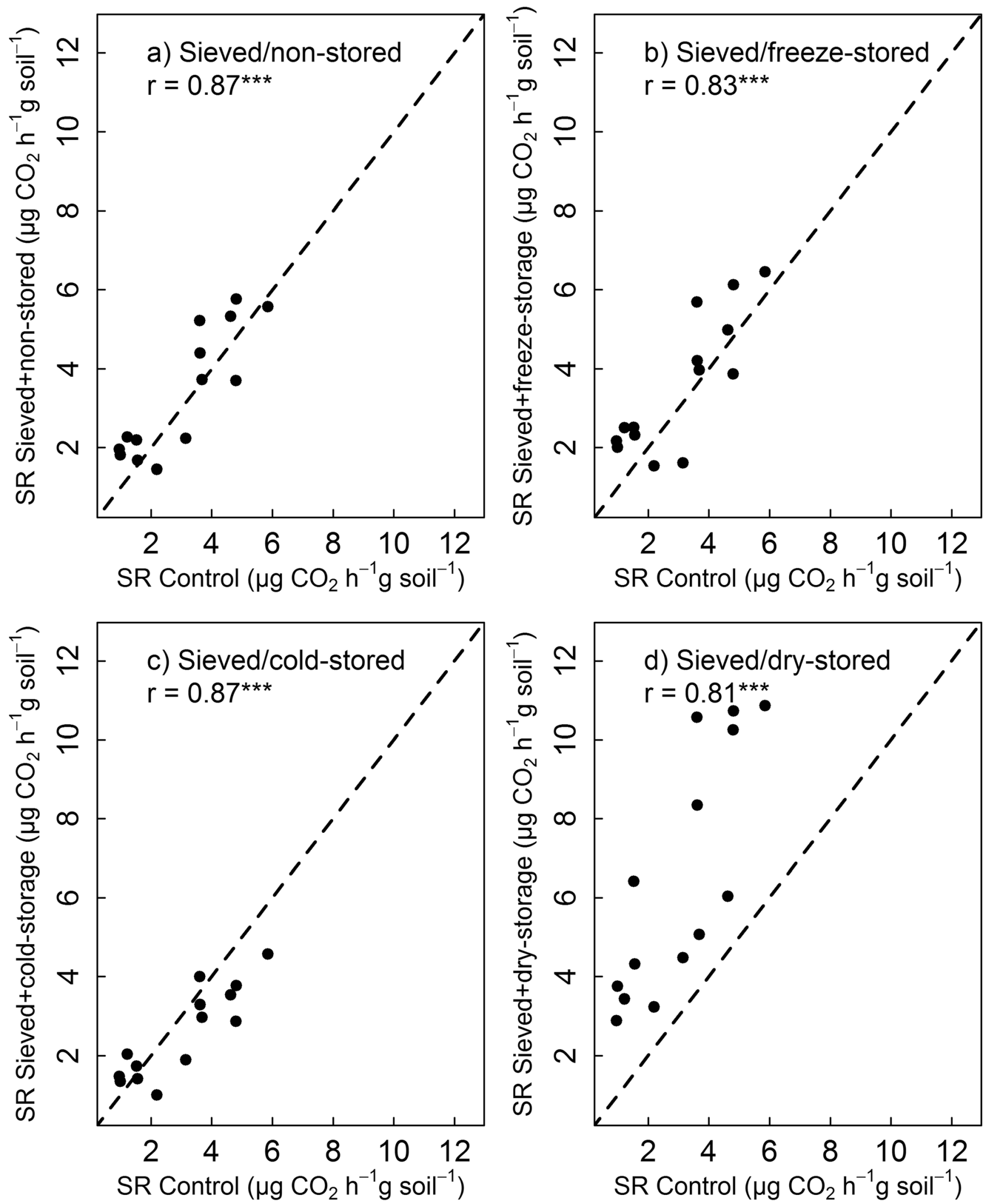

Fig. 1 Relation between $\mathrm{SR}_{25}$ measured in the four treatments and $\mathrm{SR}_{25}$ measured in the control, a for sieved/non-stored soils, $\mathbf{b}$ for sieved/freeze-stored soils, $\mathbf{c}$ for sieved/cold-stored soils, $\mathbf{d}$ for sieved/dry-stored soils 
than in moist samples. In line with our results and previous studies, we suggest that sieving at field-moist condition delivers results comparable with undisturbed conditions. Yet, we cannot exclude that sieving of dried soils leads to larger deviations as we did not compare the sieving/dry-storage treatment with dried but not sieved samples.

If soils have to be stored after sieving, cold-storage at $4{ }^{\circ} \mathrm{C}$ is generally recommended by ISO 10381-6 (1993). And indeed, we found that sieving/cold-storage had no significant effect on $\mathrm{SR}_{25}$, although a tendency towards a slight reduction of $\mathrm{SR}_{25}$ compared with the sieved/non-stored treatment ( $23 \%$ on average, $p=0.80$, Table 1) and compared with the control (Fig. 1c, $p=0.97$ ) was recognizable. A probable reason for this reduction is the finding that soil respiration takes place even at such low temperatures. Indeed, our soil respiration measurements revealed a substantial $\mathrm{CO}_{2}$ release even at $5{ }^{\circ} \mathrm{C}\left(0.87 \pm 0.76 \mu \mathrm{g} \mathrm{CO} \mathrm{h}^{-1} \mathrm{~g} \mathrm{soil}^{-1}\right.$, not shown $)$. Hence, it is probable that considerable amounts of labile and easily degradable SOC have already been mineralized within the 7 weeks of storage at $4{ }^{\circ} \mathrm{C}$, which might explain the slightly lower $\mathrm{SR}_{25}$ after cold-storage. This assumption is supported by results of Stenberg et al. (1998), who reported that soil respiration decreased with increasing duration of the coldstorage period. Although we did not measure the effect of storage duration, this suggests that storage at $4{ }^{\circ} \mathrm{C}$ delivers unbiased results only when storage duration is kept short.

While the mineralization of SOC proceeds during storage at $4{ }^{\circ} \mathrm{C}$, this is probably reduced by freeze-storage at $-18^{\circ} \mathrm{C}$. Indeed, freeze-storage had no significant effect on $\mathrm{SR}_{25}$ compared with the sieved/non-stored treatment ( $p=0.99$, Table 1) nor compared with the control (Fig. $1 b, p=0.95$ ) and there was no reduction of the mean $\mathrm{SR}_{25}$ (Table 1). This indicates that freezing largely reduces the mineralization of $\mathrm{C}$ during storage and preserves the original amount and availability of SOC.

In contrast to cold-storage and freeze-storage, only drystorage induced a significant increase of $\mathrm{SR}_{25}$ upon rewetting compared with the sieved/non-stored treatment ( $99 \%$ on average, $p<0.001$, Table 1) and compared with the control (Fig. $1 d$, $p<0.001)$. This outcome is in agreement with previous studies on drying-rewetting effects (Birch 1958; Franzluebbers 1999). The reasons for this so called Birch effect are still debated (Xiang et al. 2008) and might result from microbial stress (Schimel et al. 2007), changes in substrate supply due to aggregate disruption (Denef et al. 2001; Miller et al. 2005), or microbial death during drying with subsequent mineralization of microbial debris upon rewetting (Van Gestel et al. 1993). However, while many studies report that drying-rewetting events cause a short-term increase of SR (e.g., Franzluebbers (1999) reported that the effect lasted for 0-3 days), our results reveal that the effect was significant even after 6 days of pre-incubation at $4{ }^{\circ} \mathrm{C}$ and subsequent 5 days of incubation from 5 to $25^{\circ} \mathrm{C}$.

An effect of sample pre-processing (including both sieving and storage) on $\mathrm{SR}_{25}$ would be straightforward if it only induces an offset in the measured $\mathrm{SR}_{25}$ rate without affecting comparisons between samples. This would allow to apply a correction factor or to study spatial patterns of SR even if values might deviate from undisturbed conditions. Indeed, samples with high $\mathrm{SR}_{25}$ in the control revealed also high $\mathrm{SR}_{25}$ in the sieved and stored treatments, i.e., the rank order was similar in all treatments (Fig. 1). Thus, all samples responded rather similar to sieving and storage. This opposes Hassink et al. (Hassink 1992), who reported that sieving had larger effects in loamy than in sandy soils and Lee et al. (2007), who reported that soils with high SOC contents were more susceptible to the effects of storage. Our results suggest that each of the conducted treatments might be acceptable for deriving spatial patterns of $\mathrm{SR}_{25}$ across the landscape although it has to be kept in mind that values might considerably deviate from undisturbed conditions after dry-storage and subsequent rewetting. Hence, if storage is required after sieving, we propose that freeze-storage or shortterm cold-storage represent the best options to preserve both the real-world values and their spatial patterns.

\section{Effect of sieving and storage on Q10}

Sieving might disrupt aggregates and release $\mathrm{C}$, which was previously occluded in aggregates (Hassink 1992). In this regard, the $\mathrm{C}$ quality-temperature hypothesis predicts that the Q10 value decreases with decreasing stability of SOC, i.e., that labile SOC is less sensitive to temperature changes than stabilized or biochemically recalcitrant SOC (Bosatta and Agren 1999; Conant et al. 2008; Davidson and Janssens 2006). And indeed, Q10 values revealed a tendency to decrease upon sieving and associated aggregate disruption (Table 1, Fig. 2 a) although this effect was not significant $(p=0.19)$. The insignificance of this effect could be explained by the finding that sieving had no major effect on $\mathrm{SR}_{25}$ (sieved/not-stored, see above), which indicates that the release of previously stabilized SOC was small.

Among the sieved treatments, there was a considerable effect of storage method. Cold-storage significantly increased the Q10 value compared to the sieved/non-stored treatment (Table 1, $p=$ 0.004). Thus, sieving/cold-storage also overestimated Q10 compared to the control (Fig. 2c ) although this difference was not significant $(p=0.54)$. As supported by a lower $\mathrm{SR}_{25}$ after coldstorage, considerable amounts of labile $\mathrm{C}$ might have been mineralized during 7 weeks of cold storage. Hence, SOC might be comparatively enriched in stable and slow-cycling SOC after cold-storage. In line with the $\mathrm{C}$ quality-temperature hypothesis, Q10 values are higher for stable and slow-cycling SOC than for fresh and easily degradable SOC (Bosatta and Agren 1999; Conant et al. 2008; Davidson and Janssens 2006). This might explain the higher Q10 values after cold-storage.

In contrast, neither freeze-storage (Table $1, p=0.99$ ) nor dry-storage (Table 1, $p=0.99$ ) had a considerable effect on the Q10 value compared with the sieved/non-stored treatment. 

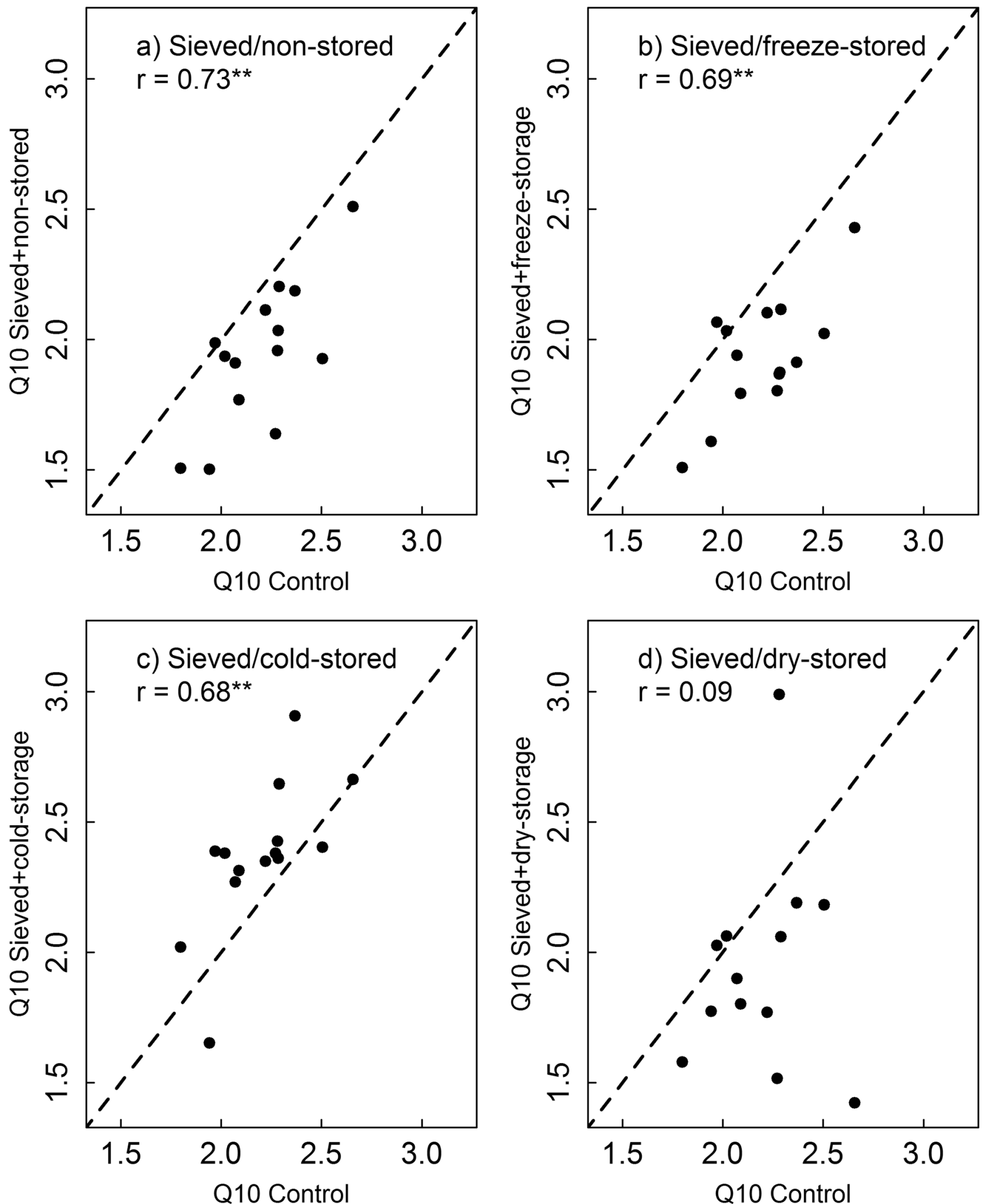

Fig. 2 Relation between Q10 values measured in the four treatments and Q10 values measured in the control, a for sieved/non-stored soils, $\mathbf{b}$ for sieved/ freeze-stored soils, $\mathbf{c}$ for sieved/cold-stored soils, $\mathbf{d}$ for sieved/dry-stored soils 
Yet, as these treatments included sieving, they revealed a tendency towards lower Q10 values compared with the control (Fig. 2, $p=0.21$ for the effect of freeze-storage and $p=0.23$ for the effect of dry-storage).

Although Q10 values were slightly over- or underestimated by sieving and/or storage, Q10 values of the sieved/non-stored, sieved/freeze-stored, and sieved/cold-stored treatments correlated with the Q10 values of the control (Fig. 2a-c). Hence, sieving and subsequent freeze- or cold-storage affected all soils similarly and did not change the general rank order from soils with low Q10 values to soils with high Q10 values. This finding did not apply to the sieving/dry-storage treatment, which induced a different rank order of Q10 values compared with the control (Fig. 2d). We conclude that sieving and subsequent cold- or freeze-storage might be acceptable for deriving spatial patterns of Q10 values across the landscape although values might slightly deviate from the undisturbed soil. In contrast, dry-storage should be avoided for the determination of spatial Q10 patterns as it does not affect all samples similarly.

\section{Conclusions}

In the case that storage and sieving of soils need to be performed in the run-up to soil respiration measurements, we conclude that sieving field-moist soil with subsequent freeze-storage or short-term cold-storage is most appropriate to conserve original soil respiration rates, their temperature sensitivity (Q10), and their original spatial patterns. A more comprehensive study is required to derive reliable correction factors that could be used for the conversion of lab-derived data into real-world soil respiration rates and Q10 values.

Acknowledgments We thank Peter Grässler, Frederike Zeibig, and Matthias Leenen for their support in field and/or laboratory work.

Funding information Open access funding provided by University of Helsinki including Helsinki University Central Hospital. This work was supported by the Collaborative Research Centre SFB/TR32 "Patterns in Soil-Vegetation-Atmosphere Systems: Monitoring, Modeling, and Data Assimilation" funded by the Deutsche Forschungsgemeinschaft (DFG).

Open Access This article is distributed under the terms of the Creative Commons Attribution 4.0 International License (http:// creativecommons.org/licenses/by/4.0/), which permits unrestricted use, distribution, and reproduction in any medium, provided you give appropriate credit to the original author(s) and the source, provide a link to the Creative Commons license, and indicate if changes were made.

\section{References}

Birch HF (1958) The effect of soil drying on humus decomposition and nitrogen availability. Plant Soil 10:9-31. https://doi.org/10.1007/ BF01343734
Bosatta E, Agren GI (1999) Soil organic matter quality interpreted thermodynamically. Soil Biol Biochem 31:1889-1891. https://doi.org/ 10.1016/S0038-0717(99)00105-4

Breulmann M, Masyutenko NP, Kogut BM, Schroll R, Dörfler U, Buscot F, Schulz E (2014) Short-term bioavailability of carbon in soil organic matter fractions of different particle sizes and densities in grassland ecosystems. Sci Total Environ 497-498:29-37. https:// doi.org/10.1016/j.scitotenv.2014.07.080

Černohlávková J, Jarkovský J, Nešporová M, Hofman J (2009) Variability of soil microbial properties: effects of sampling, handling and storage. Ecotoxicol Environ Saf 72:2102-2108. https://doi.org/ 10.1016/j.ecoenv.2009.04.023

Conant RT, Drijber RA, Haddix ML, Parton WJ, Paul EA, Plante AF, Six J, Steinweg JM (2008) Sensitivity of organic matter decomposition to warming varies with its quality. Glob Chang Biol 14:868-877. https://doi.org/10.1111/j.1365-2486.2008.01541.x

Datta R, Vranová V, Pavelka M, Rejšek K, Formánek P (2014) Effect of soil sieving on respiration induced by low-molecular-weight substrates. Int Agrophys 28:119-124. https://doi.org/10.2478/intag2013-0034

Davidson EA, Janssens IA (2006) Temperature sensitivity of soil carbon decomposition and feedbacks to climate change. Nature 440:165173. https://doi.org/10.1038/nature04514

Denef K, Six J, Paustian K, Merckx R (2001) Importance of macroaggregate dynamics in controlling soil carbon stabilization: short-term effects of physical disturbance induced by dry-wet cycles. Soil Biol Biochem 33:2145-2153. https://doi.org/10.1016/S0038-0717(01) 00153-5

Fierer N, Colman BP, Schimel JP, Jackson RB (2006) Predicting the temperature dependence of microbial respiration in soil: a continental-scale analysis. Glob Biogeochem Cycles 20:GB3026. https://doi.org/10.1029/2005GB002644

Foereid B, Ward DS, Mahowald N, Paterson E, Lehmann J (2014) The sensitivity of carbon turnover in the community land model to modified assumptions about soil processes. Earth Syst Dynam 5:211221. https://doi.org/10.5194/esd-5-211-2014

Franzluebbers AJ (1999) Potential C and N mineralization and microbial biomass from intact and increasingly disturbed soils of varying texture. Soil Biol Biochem 31:1083-1090. https://doi.org/10.1016/ S0038-0717(99)00022-X

Gritsch C, Zimmermann M, Zechmeister-Boltenstern S (2015) Interdependencies between temperature and moisture sensitivities of $\mathrm{CO}_{2}$ emissions in European land ecosystems. Biogeosciences 12:5981-5993. https://doi.org/10.5194/bg-12-5981-2015

Hamdi S, Moyano F, Sall S, Bernoux M, Chevallier T (2013) Synthesis analysis of the temperature sensitivity of soil respiration from laboratory studies in relation to incubation methods and soil conditions. Soil Biol Biochem 58:115-126. https://doi.org/10.1016/j.soilbio. 2012.11.012

Hassink J (1992) Effects of soil texture and structure on carbon and nitrogen mineralization in grassland soils. Biol Fertil Soils 14:126134. https://doi.org/10.1007/BF00336262

Herbst M, Tappe W, Kummer S, Vereecken H (2016) The impact of sieving on heterotrophic respiration response to water content in loamy and sandy topsoils. Geoderma 272:73-82. https://doi.org/ 10.1016/j.geoderma.2016.03.002

ISO 10381-6 (1993) Soil quality - sampling. Guidance on the collection, handling and storage of soil for the assessment of aerobic microbial processes in the laboratory. International Organization for Standardization, Geneva, Switzerland

Juarez S, Nunan N, Duday AC, Pouteau V, Schmidt S, Hapca S, Falconer R, Otten W, Chenu C (2013) Effects of different soil structures on the decomposition of native and added organic carbon. Eur J Soil Biol 58:81-90. https://doi.org/10.1016/j.ejsobi.2013.06.005

Kirschbaum M (1995) The temperature dependence of soil organic matter decomposition, and the effect of global warming on soil organic $\mathrm{C}$ 
storage. Soil Biol Biochem 27:753-760. https://doi.org/10.1016/ 0038-0717(94)00242-S

Kirschbaum M (2006) The temperature dependence of organic-matter decomposition - still a topic of debate. Soil Biol Biochem 38: 2510-2518. https://doi.org/10.1016/j.soilbio.2006.01.030

Lamparter A, Bachmann J, Goebel MO, Woche SK (2009) Carbon mineralization in soil: impact of wetting-drying, aggregation and water repellency. Geoderma 150:324-333. https://doi.org/10.1016/j. geoderma.2009.02.014

Lee YB, Lorenz N, Dick LK, Dick RP (2007) Cold storage and pretreatment incubation effects on soil microbial properties. Soil Sci Soc Am J 71:1299-1305. https://doi.org/10.2136/sssaj2006.0245

Lefèvre R, Barré P, Moyano FE, Christensen BT, Bardoux G, Eglin T, Girardin C, Houot S, Kätterer T, van Oort F, Chenu C (2014) Higher temperature sensitivity for stable than for labile soil organic carbon evidence from incubations of long-term bare fallow soils. Glob Chang Biol 20:633-640. https://doi.org/10.1111/gcb.12402

Lomander A, Kätterer T, Andrén O (1998) Modelling the effects of temperature and soil moisture on $\mathrm{CO}_{2}$ evolution from top- and subsoil using a multi-compartment approach. Soil Biol Biochem 30:20232030. https://doi.org/10.1016/S0038-0717(98)00077-7

Meyer N, Welp G, Bornemann L, Amelung W (2017) Microbial nitrogen mining affects spatio-temporal patterns of substrate-induced respiration during seven years of bare fallow. Soil Biol Biochem 104:175184. https://doi.org/10.1016/j.soilbio.2016.10.019

Meyer N, Welp G, Amelung W (2018) The temperature sensitivity (Q10) of soil respiration: controlling factors and spatial prediction at regional scale based on environmental soil classes. Glob Biogeochem Cycles 32:306-323. https://doi.org/10.1002/2017GB005644

Miller KS, Geisseler D (2018) Temperature sensitivity of nitrogen mineralization in agricultural soils. Biol Fertil Soils 54:853-860. https:// doi.org/10.1007/s00374-018-1309-2

Miller AE, Schimel JP, Meixner T, Sickman JO, Melack JM (2005) Episodic rewetting enhances carbon and nitrogen release from chaparral soil. Soil Biol Biochem 37:2195-2204. https://doi.org/10. 1016/j.soilbio.2005.03.021

Nordgren A (1988) Apparatus for the continuous, long-term monitoring of soil respiration rate in large numbers of samples. Soil Biol Biochem 20:955-957. https://doi.org/10.1016/0038-0717(88) 90110-1

Potter CS, Randerson JT, Field CB, Maston PA, Vitousek PM, Mooney HA, Klooster SA (1993) Terrestrial ecosystem production: a process model based on global satellite and surface data. Glob Biogeochem Cycles 7:811-841. https://doi.org/10.1029/93GB02725

R Core Team (2013) R: A language and environment for statistical computing. R Foundation for Statistical Computing. Vienna, Austria. URL http://www.R-project.org/

Raich JW, Rastetter EB, Melillo JM, Kicklighter DW, Steudler PA, Peterson BJ, Grace AL, Moore B, Vörösmarty CJ (1991) Potential net primary productivity in South America: application of a global model. Ecol Appl 1:399-429. https://doi.org/10.2307/1941899
Reichstein M, Subke JA, Angeli AC, Tenhunen JD (2005) Does the temperature sensitivity of decomposition of soil organic matter depend upon water content, soil horizon, or incubation time? Glob Chang Biol 11:1754-1767. https://doi.org/10.1111/j.1365-2486. 2005.001010.x

Schimel J, Balser TC, Wallenstein M (2007) Microbial stress-response physiology and its implications for ecosystem function. Ecology 88: 1386-1394. https://doi.org/10.1890/06-0219

Smith VR (2005) Moisture, carbon and inorganic nutrient controls of soil respiration at a sub-Antarctic island. Soil Biol Biochem 37:81-91. https://doi.org/10.1016/j.soilbio.2004.07.026

Stenberg B, Johansson M, Pell M, Sjödahl-Svensson K, Stenström J, Torstensson L (1998) Microbial biomass and activities in soil as affected by frozen and cold storage. Soil Biol Biochem 30:393402. https://doi.org/10.1016/S0038-0717(97)00125-9

Thomson BC, Ostle NJ, McNamara NP, Whiteley AS, Griffiths RI (2010) Effects of sieving, drying and rewetting upon soil bacterial community structure and respiration rates. J Microbiol Methods 83:69-73. https://doi.org/10.1016/j.mimet.2010.07.021

Van 't Hoff JH (1898) Lectures on theoretical and physical chemistry. In: Chemical dynamics part I. Edward Arnold, London, pp 224-229

Van Gestel M, Merckx R, Vlassak K (1993) Microbial biomass responses to soil drying and rewetting: the fate of fast- and slow-growing microorganisms in soils from different climates. Soil Biol Biochem 25:109-123. https://doi.org/10.1016/0038-0717(93) 90249-B

Wang Q, He N, Yu G, Gao Y, Wen X, Wang R, Koerner SE, Yu Q (2016) Soil microbial respiration rate and temperature sensitivity along a north-south forest transect in eastern China: patterns and influencing factors. J Geophys Res Biogeosci 121:399-410. https://doi.org/10. 1002/2015JG003217

Xiang S, Doyle A, Holden PA, Schimel JP (2008) Drying and rewetting effects on $\mathrm{C}$ and $\mathrm{N}$ mineralization and microbial activity in surface and subsurface California grassland soils. Soil Biol Biochem 40: 2281-2289. https://doi.org/10.1016/j.soilbio.2008.05.004

Xiao H, Li Z, Chang X, Deng L, Nie X, Liu C, Liu L, Jiang J, Chen J, Wang D (2018) Microbial $\mathrm{CO}_{2}$ assimilation is not limited by the decrease in autotrophic bacterial abundance and diversity in eroded watershed. Biol Fertil Soils 54:595-605. https://doi.org/10.1007/ s00374-018-1284-7

Zelles L, Adrian P, Bai QY, Stepper K, Adrian MV, Fischer K, Maier A, Ziegler A (1991) Microbial activity measured in soils stored under different temperature and humidity conditions. Soil Biol Biochem 23:955-962. https://doi.org/10.1016/0038-0717(91)90176-K

Publisher's note Springer Nature remains neutral with regard to jurisdictional claims in published maps and institutional affiliations. 